P0131

\title{
INFLUENCE OF COLOR TEMPERATURE AND INTERIOR REFLECTANCE ON SPATIAL BRIGHTNESS DEMAND \\ Mika Kato
}

DOI 10.25039/x46.2019.PO131

from

CIE x046:2019

Proceedings

of the

29th CIE SESSION

Washington D.C., USA, June 14 - 22, 2019

(DOI 10.25039/x46.2019)

The paper has been presented at the 29th CIE Session, Washington D.C., USA, June 14-22, 2019. It has not been peer-reviewed by CIE.

(C) CIE 2019

All rights reserved. Unless otherwise specified, no part of this publication may be reproduced or utilized in any form or by any means, electronic or mechanical, including photocopying and microfilm, without permission in writing from CIE Central Bureau at the address below. Any mention of organizations or products does not imply endorsement by the CIE.

This paper is made available open access for individual use. However, in all other cases all rights are reserved unless explicit permission is sought from and given by the CIE.

CIE Central Bureau

Babenbergerstrasse 9

A-1010 Vienna

Austria

Tel.: +4317143187

e-mail: ciecb@cie.co.at

www.cie.co.at 


\title{
INFLUENCE OF COLOR TEMPERATURE AND INTERIOR REFLECTANCE ON SPATIAL BRIGHTNESS DEMAND
}

\author{
Kato, M. ${ }^{1}$ \\ ${ }^{1}$ Nihon University, Chiba, JAPAN \\ kato.mika@nihon-u.ac.jp
}

DOI 10.25039/x46.2019.PO131

\begin{abstract}
This report shows the results of two experiments on spatial brightness in a space with different color temperature and interior reflectance. Experiment 1 compared the perception of "spatial brightness". Experiment 2 compared the demand of "spatial brightness" for specific use.

The perception of spatial brightness showed the relation $3000 \mathrm{~K}=4000 \mathrm{~K} \neq 5000 \mathrm{~K}=6000 \mathrm{~K}$. The higher the color temperature, the higher the perception of spatial brightness tends to be.

And, the spatial brightness demand tended to be higher as the color temperature was lower, regardless of the room usage. And when the interior reflectance is high, there is a tendency that the average luminance of the space that answers "just right brightness" increases.
\end{abstract}

Keywords: Spatial Brightness, Color Temperature, Interior Retlectance, Room Use

\section{Introduction}

In recent years, much research on spatial brightness has been done, especially in Japan. These studies explain the spatial brightness by the luminance distribution of the observing scene. And these are targeted for perception of spatial brightness.

However, for design, "how much spatial brightness is required" is more important than "how much spatial brightness perceives". Therefore, it is urgent to investigate the demand for spatial brightness according to space usage.

However, it is doubtful whether the space usage and the required spatial brightness are consistent. For example, some people like the impression of calm for the space for meals, others like gorgeous impression. I do not think they both want the same spatial brightness.

A large amount of light is necessary to make the space composed of the low reflectance interior material and the space formed of the high reflectance interior material identical. But is there really such a space required? If you want to create a space that feels bright, increase the reflectivity of the interior material and lower it if you want to create a quiet impression space. That is, it can be predicted that there is regularity in the relationship between spatial brightness demand and interior reflectance.

Also known as a Kruithof curve ${ }^{1)}$, preferred illuminance tends to differ depending on color temperature. It is said that low illuminance is accepted at low color temperature and high illuminance is accepted at high color temperature. If the illuminance and the spatial brightness are regarded as almost equivalent, the color temperature is also considered to affect it.

Therefore, in this research, we investigated the influence of interior reflectance and color temperature on the demand of spatial brightness according to the room use.

\section{Experiment method}

\subsection{Experimental space}

Experiments were conducted using a scale of $1 / 6$ model. The size is $8 \mathrm{Jo}$-ma (the size of a general room of a Japanese housing : $3.6 \mathrm{~m}^{*} 3.6 \mathrm{~m}^{*} 2.4 \mathrm{~m}$ ). A light is installed in the center of the 
ceiling. The size is $60 \mathrm{~cm}{ }^{*} 60 \mathrm{~cm}$. An opening for observation was provided at a position corresponding to a height of $120 \mathrm{~cm}$. Figure 1 shows the dimensions of the model.

The experimental variables are color temperature and interior reflectance.

The color temperature was set to 4 kinds, $3000 \mathrm{~K}, 4000 \mathrm{~K}, 5000 \mathrm{~K}, 6000 \mathrm{~K}$. The LED equipment used for experiment prepared 2 types of 4000K (Panasonic: XL584PFU LT9) and 5000K (Panasonic: XL584PFV LT9). 3000K and 5000K used color temperature change filters (Leefilter: $442,218)$. The color temperatures measured in the experimental space were $2858 \mathrm{~K}$ for $3000 \mathrm{~K}$, $3857 \mathrm{~K}$ for $4000 \mathrm{~K}, 4867 \mathrm{~K}$ for $5000 \mathrm{~K}$, and $5853 \mathrm{~K}$ for $6000 \mathrm{~K}$.

The illuminance was set to 6 levels (32lx, 63lx, 125lx, 250lx,500lx, 1000lx) with a dimmer. Setting value is equal pitch on logarithmic axis.

There are three types of interior reflectance, $\mathrm{N} 4.5(11.4 \%), \mathrm{N} 7.5(45.7 \%)$ and $\mathrm{N} 9.5(77.5 \%)$. In addition, three reflectance $(11.4 \%, 45.7 \%, 77.5 \%)$ cubes are placed in the evaluation space to make the perception of lightness accurate. Table 1 shows the photographs showing the inside of the experimental space.

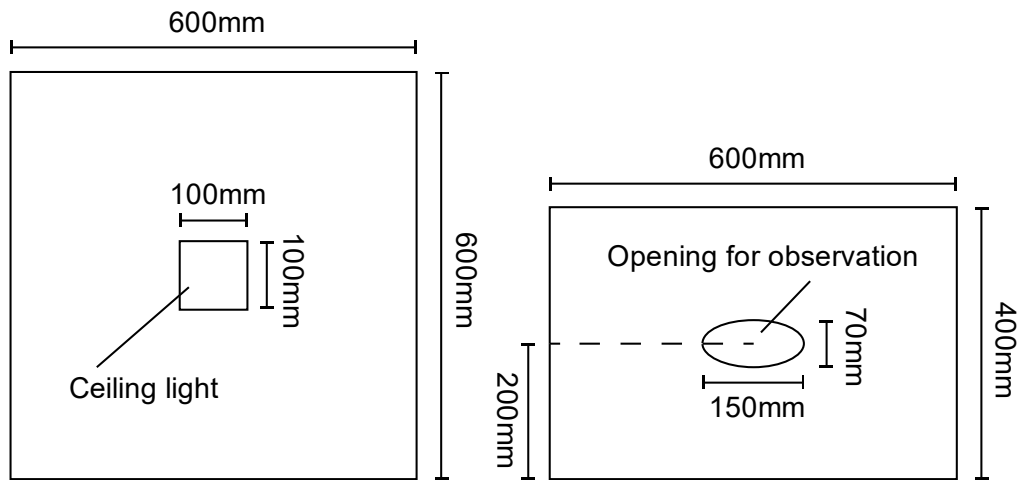

Figure 1 - Size of the experiment space : $1 / 6$ scale model

Table 1- State inside the evaluation space

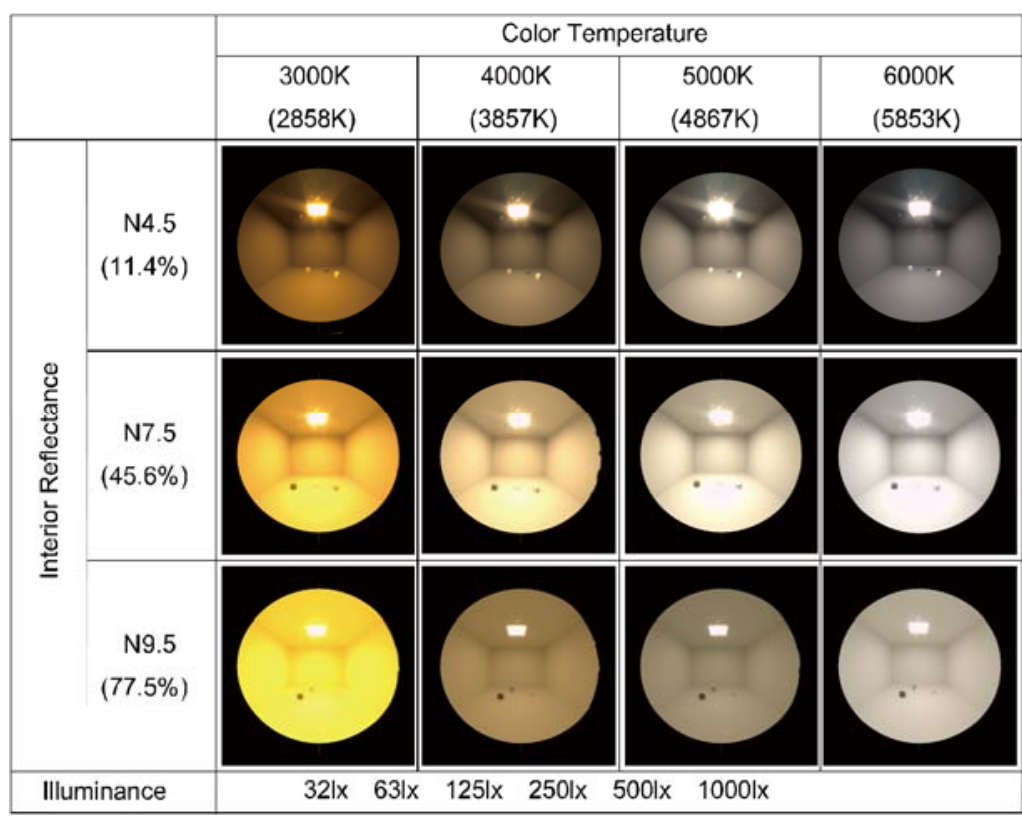




\subsection{Method for evaluation}

Two types of experiments were conducted. The first is to evaluate the perception of spatial brightness, as in previous studies. The other is to evaluate the spatial brightness required for use in each room.

\subsubsection{Experiment on perception of spatial brightness (Experiment 1)}

This evaluation was done with the magnitude estimation method. In the reference space, the floor surface is $\mathrm{N} 4$, the wall surface is $\mathrm{N} 7.5$, and the ceiling surface is $\mathrm{N9}$, the color temperature is $5000 \mathrm{~K}$, and the illuminance is set to $300 \mathrm{~lx}$ at the center of the room. An overview of the reference space is shown in Table 3.

The evaluation space of this experiment is the condition of four color temperatures and an interior reflectance of N4.5 and N9.5. There are six levels of illuminance shown in Table 1.

The experimental procedure is described. First, observe the reference space for 20 seconds and store an impression. After that, an evaluation space is observed for 20 seconds to evaluate the spatial brightness. The brightness of the reference space is 100 , and the brightness of the evaluation space is answered with a positive integer. What is evaluated in this experiment is how bright it is perceived relative to the reference space. The presentation order of evaluation space is random.

The number of subjects is 19 males and 1 female in their twenties.

Table 2 - Outline of the reference space

\begin{tabular}{|c|c|c|c|}
\hline Interior Reflectance & $\begin{array}{c}\text { Color } \\
\text { Temperature }\end{array}$ & Illuminance & $\begin{array}{c}\text { State inside the } \\
\text { model }\end{array}$ \\
\cline { 1 - 1 } $\begin{array}{c}\text { Floor } \\
\text { N4(10.5\%) }\end{array}$ & & & \\
\cline { 1 - 1 } Wall & & & \\
N7.5(45.7\%) & $\left(\begin{array}{l}5000 \mathrm{~K} \\
4867 \mathrm{~K})\end{array}\right.$ & $300 \mathrm{~lx}$ & \\
\cline { 1 - 1 } $\begin{array}{c}\text { Ceiling } \\
\text { N9(83.9\%) }\end{array}$ & & & \\
\hline
\end{tabular}

\subsubsection{Experiments for the demand of spatial brightness (Experiment 2)}

Five purposes of using the evaluation space were set, "talk while relaxing at home", "relaxing alone", "studying", "reading books", "watching TV". The subject observes the evaluation space and evaluates whether the spatial brightness is appropriate or not, assuming the specified use.

The evaluation scale is seven stages shown below.

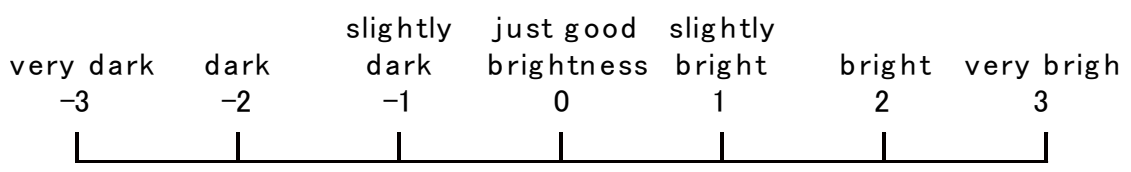

For example, if the spatial brightness of the evaluation space is considered appropriate for space use, the subject selects 0 .

Subject is the same as Experiment 1 and all Japanese. The acclimation time is the same as in Experiment 1 and is 20 seconds. The presentation order of evaluation space is random.

\section{Experimental result and consideration}

\subsection{Result of Experiment 1}

Figure 2 shows the relationship between the spatial brightness evaluation value and the mean luminance for each color temperature. There is no difference between the N4.5 and N9.5 trends in any color temperature, and the interior reflectance has no effect on the perception of spatial brightness. 
Figure 3 is a graph in which the approximation formula for each color temperature shown in Figure 2 is superimposed on one graph. Looking at this graph, $3000 \mathrm{~K}$ and $4000 \mathrm{~K}$ are almost equal, and $5000 \mathrm{~K}$ and $6000 \mathrm{~K}$ are almost equal. And the latter seems to feel brighter. There have been reports in the past that the higher the color temperature, the higher the perception of brightness.

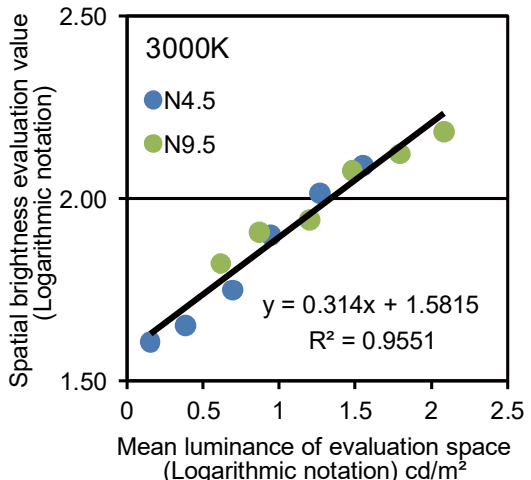

(Logarithmic notation) $\mathrm{cd} / \mathrm{m}^{2}$

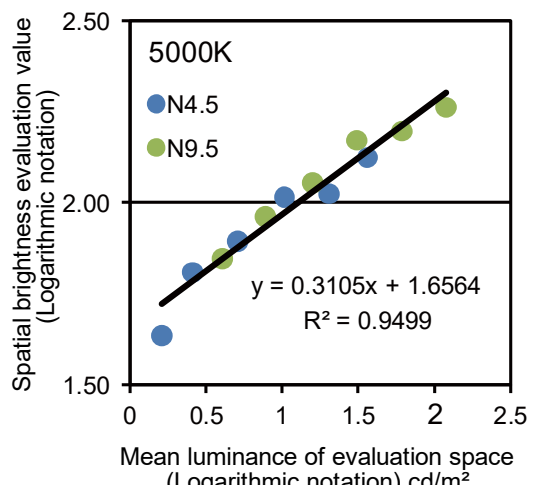

(Logarithmic notation) $\mathrm{cd} / \mathrm{m}^{2}$

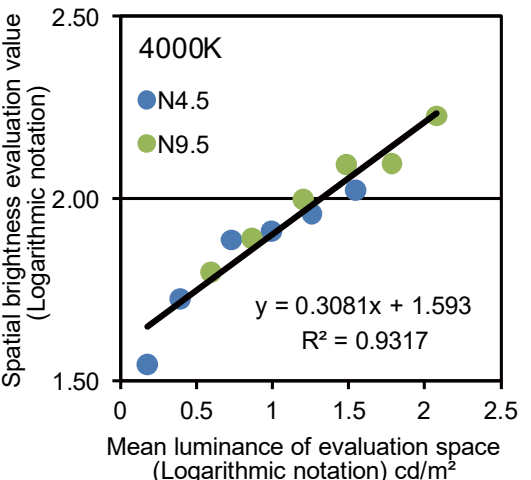

(Logarithmic notation) $\mathrm{cd} / \mathrm{m}^{2}$

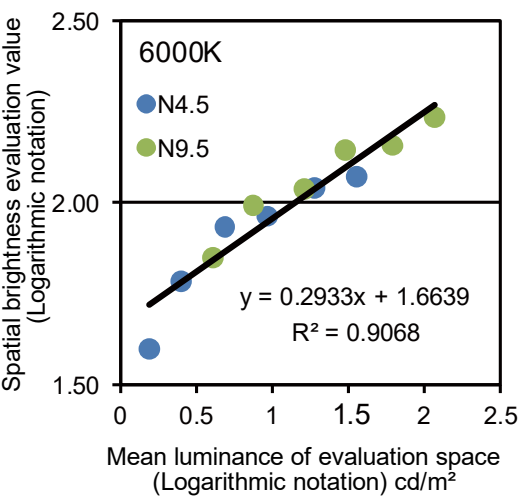

(Logarithmic notation) $\mathrm{cd} / \mathrm{m}^{2}$

Figure 2 - Influence of interior reflectance (for each color temperature)

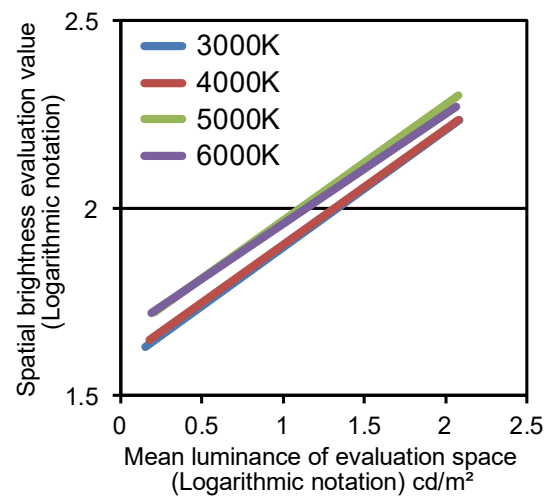

Figure 3 - Color temperature comparison

\subsection{Result of Experiment 2}

The following shows how to find the mean luminance where the spatial brightness is " just good brightness".

Figure 4 shows an example of the relationship between the mean of seven evaluation values and the mean luminance of the evaluation space. First, find an approximate expression for each interior reflectance (See the green letters in Figure 4). Next, find the $y$ value when the $x$ axis value is 0 (See the red arrow in Figure 4).

Figure 5 shows the mean luminance obtained by the above procedure. First of all, looking at the influence of color temperature, regardless of the specified use, the higher the color 
temperature, the lower the mean luminance, which feels "brightness is just right". However, the trend is different for $6000 \mathrm{~K}$. It is a result different from the tendency shown by Kruithof.

Next, the influence of interior reflectance is compared. The overall trend is that the higher the interior reflectance, such as N4.5, N.7.5, N9.5, the higher the mean luminance. According to the result of Experiment 1, if the average luminance is the same, even if the interior reflectance is different, it is perceived as the same brightness. Based on this, it is considered that the higher the interior reflectance, the higher the spatial brightness is required.

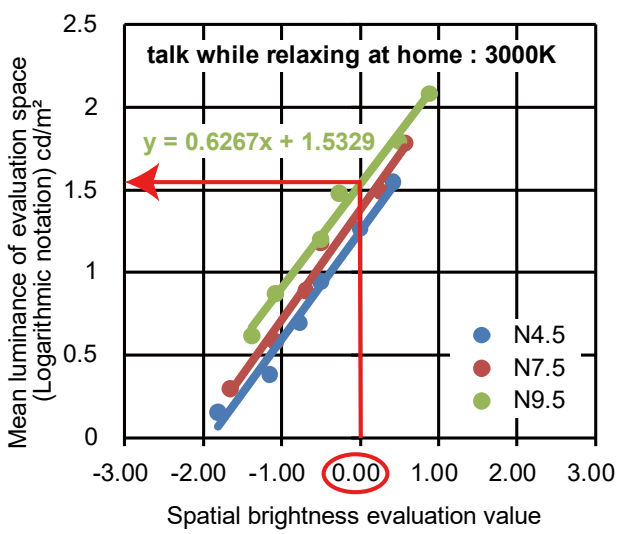

Figure 4 - How to find the mean luminance corresponding to "just good brightness"
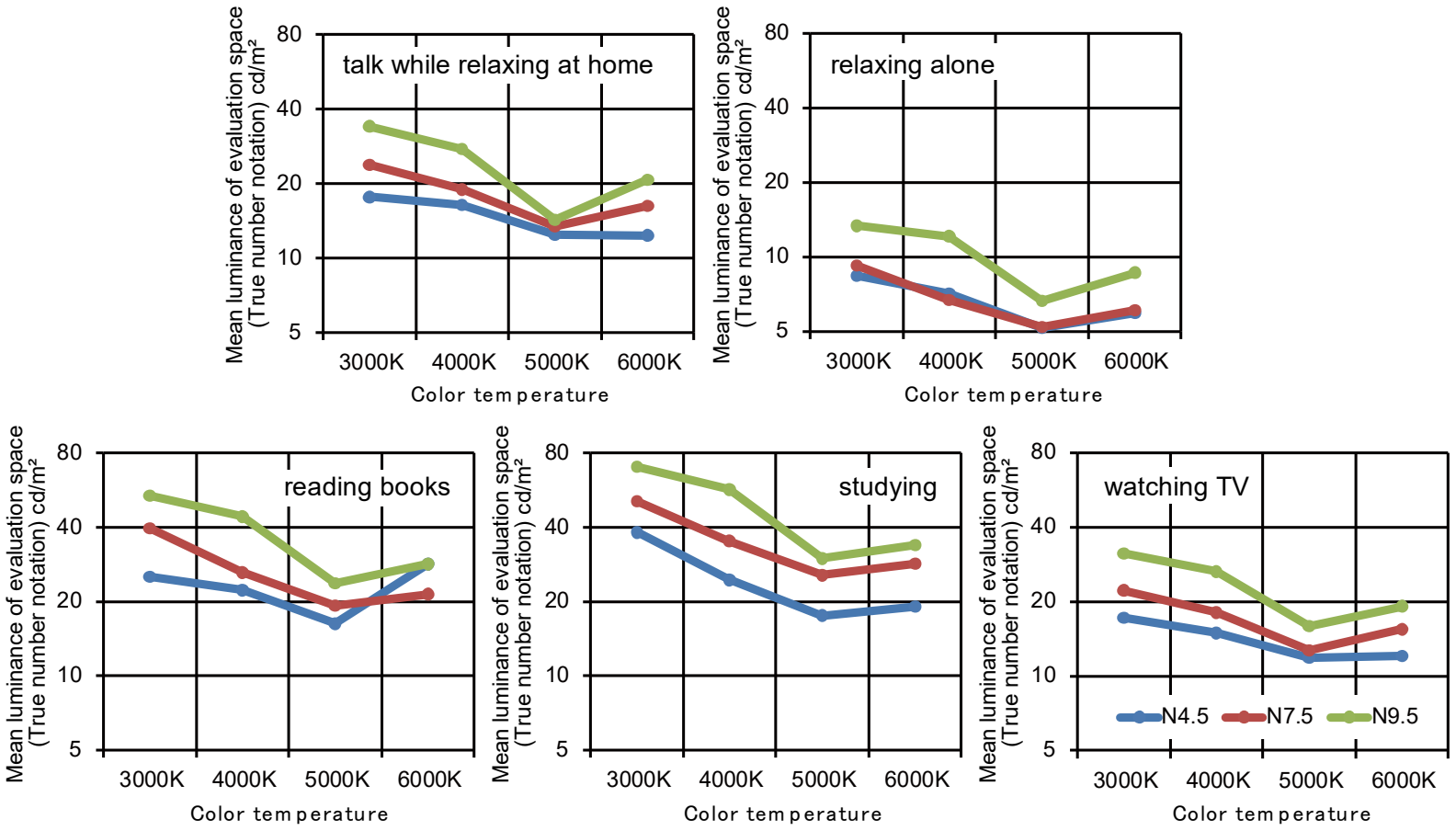

Figure 5 - Mean luminance to feel as "just good brightness"

\section{Conclusions}

From the above results, it became clear that the color temperature and interior reflectance affected the spatial brightness demand. This result means that even if the use is the same, given the same spatial brightness (or mean luminance) does not necessarily lead to the same satisfaction.

According to existing standards, the mean luminance and illuminance of ceilings and walls according to the use of the room are determined, but a target value according to room situation 
will be required. The placement of lighting fixtures may also affect it, so experiment will be continued.

As mentioned above, the result of this report is the experiment of the subjects living in Japan. How much space brightness is required is likely to be influenced by the light environment experienced so far. If the functions of the eyes are the same, the amount of light necessary for visual work is the same, but the spatial brightness needs to take into account the influence of cultural background. These may be one reason why the results are different from kruithof's tendency.

In the future, it may be necessary to consider not only the design criteria based on perception but also the viewpoint that requirements (preferences) are satisfied.

\section{Reference}

1. Kruithof, A. A., Tubular Luminescence Lamps for General Illumination, Philips Technical Review 6, 65-96 (1941) 